Portland State University

PDXScholar

7-1972

\title{
An Investigation of Temporary Threshold Shift Among Helmeted Motorcycle Riders
}

Alamander Hicks

Portland State University

Follow this and additional works at: https://pdxscholar.library.pdx.edu/open_access_etds

Part of the Speech and Hearing Science Commons, and the Speech Pathology and Audiology Commons

Let us know how access to this document benefits you.

\section{Recommended Citation}

Hicks, Alamander, "An Investigation of Temporary Threshold Shift Among Helmeted Motorcycle Riders" (1972). Dissertations and Theses. Paper 1566.

https://doi.org/10.15760/etd.1566

This Thesis is brought to you for free and open access. It has been accepted for inclusion in Dissertations and Theses by an authorized administrator of PDXScholar. Please contact us if we can make this document more accessible: pdxscholar@pdx.edu. 
AN ABSTRACT OF THE THESIS OF Alamander Hicks for the Master of Science in Speech with a major emphasis in Speech Pathology and Audiology presented July 10, 1972.

Title: An Investigation of Temporary Threshold Shift Among Helmeted Motorcycle Riders

APPROVED BY MEMBERS OF THE THESIS COMMITTEE:

James F, Magurer, Ph.D., Chairman Robert H. English, R.Ed.

tane C. Norris, M.A.

The purpose of the present study involved the investigation of the significance of wind noise as a contributing factor toward temporary threshold shifts among a select sample of motorcycle riders.

Five normal-hearing, helmeted, female subjects were administered pure-tone air-conduction hearing tests immediately before and within 2 minutes after exposure to three noise-related aspects of motorcycle riding. The amount of hearing loss present at $3 \mathrm{k}, 4 \mathrm{k}$ and $6 \mathrm{k} \mathrm{Hz}$ after each $20 \mathrm{~min}-$ 
ute exposure condition was recorded as the TTS for that subject. The three conditions consisted of motorcycle noise only, wind noise only and motorcycle and wind noise combined.

A statistical analysis of the data revealed that motorcycle noise alone produced significantly less TTS than the wind only or the wind and motorcycle noise. These findings support the hypothesis that wind noise is a significant factor in the production of TTS and possible noise-induced hearing loss among motorcycle riders. 
AN INVESTIGATION OF TEMPORARY THRESHOLD SHIFT

AMONG HELMETED MOTORCYCLE RIDERS

by

ALAMANDER HICKS

A thesis submitted in partial fulfillment of the requirements for the degree of

\section{MASTER OF SCIENCE}

in

SPEECH

with emphasis in Speech Pathology

and Audiology

Portland State University

1972 
TO THE OFFICE OF GRADUATE STUDIES:

The members of the Thesis Committee approve the thesis of Alamander Hicks presented July 21, 1972.

James Maurer, Ph.D., Chairman

Robert H. English, D.r.

Jatie C. Norris, M.A.

APPROVED :

Robert $\bar{W}$. Vogelsang/Chairman/ Department of speech

Dakid T. Clark, Dean of Graduate Studies

July 28, 1972 


\section{ACKNOWLEDGEMENTS}

I wish to express my sincere gratitude and appreciation to Dr. James F. Maurer, my thesis committee chairman, for the kind of unremitting guidance and encouragement that made this investigation possible - a very special thanks to a very exceptional person.

Special gratitude is expressed to Mrs. Judy Widen for sharing her expertise and technical assistance in the gathering and statistical analysis of the data.

My sincere appreciation is extended to my brother Steve, my sister Hilda, and their friends for their many hours of assistance in accomplishing this investigation. My deepest and most sincere thanks go to my sister Pat. Her efforts in behalf of this study were numerous and diligent.

I wish to acknowledge the support and encouragement given by Dr. Robert English and Mrs. Jane Norris, the other members of my thesis committee.

Finally, I wish to thank my wife Judy for her efforts and patience with me during this very trying investigation. 
TABLE OF CONTENTS

PAGE

ACKNOWLEDGEMENTS $\ldots \ldots \ldots \ldots \ldots \ldots \ldots \ldots \ldots \ldots \ldots \ldots \ldots \ldots \ldots$

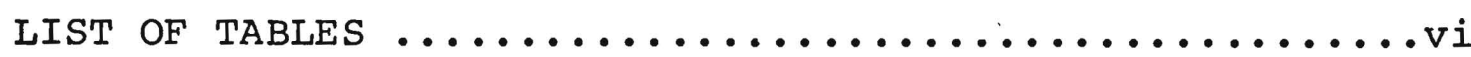

LIST OF FIGURES $\ldots \ldots \ldots \ldots \ldots \ldots \ldots \ldots \ldots \ldots \ldots \ldots \ldots \ldots \ldots$

CHAPTER

I INTRODUCTION $\ldots \ldots \ldots \ldots \ldots \ldots \ldots \ldots \ldots \ldots \ldots \ldots$

II HISTORY OF THE PROBLEM $\ldots \ldots \ldots \ldots \ldots \ldots \ldots \ldots$

NOISE-INDUCED HEARING LOSSES $\ldots \ldots \ldots \ldots \ldots \ldots$

Frequency

Intensity

Duration

Type of Noise

CONSEQUENCES OF NOISE ON HEARING THRESHOLDS $\ldots 6$ TEMPORARY THRESHOLD SHIFT $\ldots \ldots \ldots \ldots \ldots \ldots \ldots$ CONSEQUENCES OF NOISE ON MOTORCYCLE RIDERS ....10

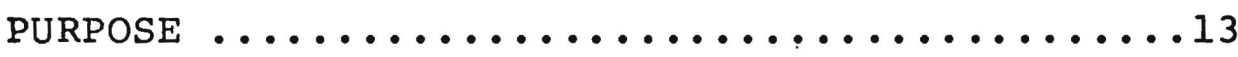

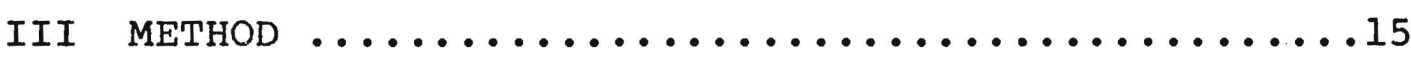

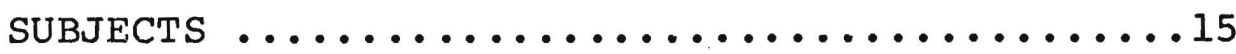

EQUIPMENT $\ldots \ldots \ldots \ldots \ldots \ldots \ldots \ldots \ldots \ldots \ldots \ldots \ldots \ldots \ldots \ldots \ldots \ldots \ldots$

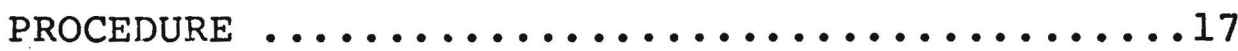

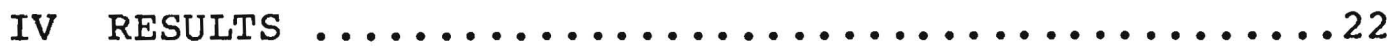

PRESENTATION OF RESULTS $\ldots \ldots \ldots \ldots \ldots \ldots \ldots \ldots \ldots \ldots$

DISCUSSION OF RESULTS $\ldots \ldots \ldots \ldots \ldots \ldots \ldots \ldots$

$\mathrm{v}$ CONCLUSIONS AND IMPILICATIONS $\ldots \ldots \ldots \ldots \ldots \ldots \ldots$ 


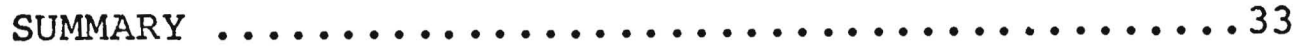

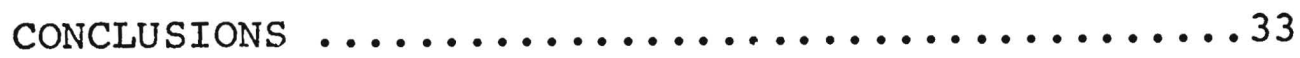

IMPLICATIONS FOR FURTHER RESEARCH .............34

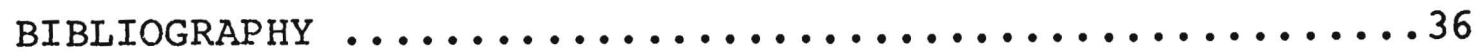




\section{LIST OF TABLES}

TAPLE

PAGE

I SUMMARY OF TEMPORARY THRESHOLD SHIFT AFTER

A 20 MINUTE EXPOSURE TO THREE

DIFFERENT . NOISE CONDITIONS .........23

II MEAN TTS AND STANDARD DEVIATIONS ASSOCIATED

WITH THE THREE TREATMENT CONDITIONS ARE

EXPRESSED. THIS TABLE REPORTS T SCORES

COMPARING THE MEAN DIFFERENCES OF. THE

VARIOUS CONDITIONS .............26 


\section{IIST OF FIGURES}

FIGURE

PAGE

I OCTAVE BAND ANALYSIS OF THE MOTORCYCLE

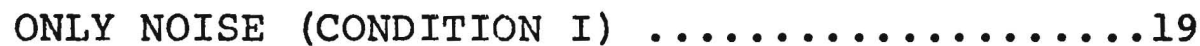

2 COMPARISON OF MEAN THRESHOLD SHIFTS AT EACH

FREQUENCY FOR THE THREE DIFFERENT

EXPOSURE CONDITIONS ............24

3 INDIVIDUAL THRESHOI.D SHIFTS AT 3K, 4K AND 6K

HZ ASSOCIATED WITH THREE

NOISE CONDITIONS .............28 
CHAPTER I

\section{INTRCDUCTION}

Noise has been loosely defined as any unwanted sound. Whether present in the occupational environment or in the recreational milieu, noise has an effect upon man at two levels. One level, annoyance, is quite general. The second level, physical damage to the auditory mechanism, is very specific.

At the annoyance level, continuous exposure to noise disturbs the keen balances maintained by the body physiology. Stress produced by continuous noise exposure has been listed as the cause of numerous physiological reactions. Constriction of blood vessels during exposure to noise gives rise to increased blood pressure. Heart rate increases, the musculature tenses, perspiration tends to increase, adrenalin output rises markedly and the kidneys become more active. Changes in brain chemistry have been discovered. Cumulatively, these temporary physiologic responses tend to influence the general state of the exposed subject, producing annoyance (Broadbent, 1957, 1958; Glorig, 1970; Lipscomb, 1970). Emotional responses to noise have been found to contribute to lowered productivity and increased worker errors in industry (Broadbent, 1957, 1958; Lipscomb, 1970). Evi- 
dence is accumulating which would support the thesis that an inordinately high environmental noise level plays a large part in causing industrial accidents (Broadbent, 1957, 1958; Glorig, 1970; Lipscomb, 1970; Ward, 1963). It also is well established that very loud noises have the capability of destroying the thousands of tiny, delicate sensory cells which play a major role in the function of the hearing sense (Lipscomb, 1970; Ward, 1963).

Because of increasing industrialization in society, ranging from mechanized labor saving devices in the home to increasing noise levels in business and industry, noise is an increasing pollutant (Glorig, 1970; Lipscomb, 1970). Hearing levels for the average American tend to be poorer than those of individuals from more primitive societies (Glorig, 1970). Main thrusts among researchers are: (1) to investigate new methods for reducing noise, and (2) to discover new sources of noise pollution. It is toward the latter area that the present research is directed. 


\section{HISTORY OF THE PROBLEM}

\section{NOISE-INDUCED HEARING LOSSES}

The human ear is not equally sensitive to all noises in the audible range of hearing. Some noises are more dangerous to the hearing mechanism than others. The deleterious effects of noise on hearing are influenced by frequency spectra, intensity, duration and type of noises (continuous or intermittent).

\section{Frequency}

The destructive capability of noise as a function of frequency is not well established. It is felt, however, that the spectral composition of a noise stimulus contributes to its damage potential. The maximum effect on hearing after high-level noise exposure generally j.s found one-half to one octave above the upper cutoff frequency of the noise (Ward, 1962a, 1963). Two reasons help explain this phenomenon: 1) the middle ear transmits the frequencies between 1000 and $4000 \mathrm{~Hz}$ most efficiently, so that more energy reaches the inner ear in this range; and 2) a given area of the inner ear is affected by a wide range of frequencies below its characteristic frequencies, but not by those above; therefore, all of the most intense 
noise elements affects the $4000 \mathrm{~Hz}$ receptors (Ward, 1962a, 1965, 1969). If a broad-band noise includes frequencies up to $3000 \mathrm{~Hz}$, the maximum effect on audition will be produced at $4 \mathrm{k}, 5 \mathrm{k}$ or $6 \mathrm{k} \mathrm{Hz}$ regardless of whether there is energy at higher frequencies. A safe generalization seems to be that the higher the frequency of the noise, up to approximately $3000 \mathrm{~Hz}$, the more noise-induced hearing loss will be produced. Therefore, damage-risk criteria (intensity limits of noise that can be tolerated without serious risk of permanent hearing loss) generally permit exposure to higher levels of noise in the $150-300 \mathrm{~Hz}$ and $300-600 \mathrm{~Hz}$ octave bands than in the $600-1200 \mathrm{~Hz}$ and $1200-2400 \mathrm{~Hz}$ octave bands (Ward, 1962a; Ward, et al., 1959, 1960). That is, a rumble is less dangerous than a screech.

\section{Intensity}

It is a well established fact that hearing thresholds are adversely affected as the intensity of the noise increases. Exactly how this occurs depends upon all the other parameters (Ward, 1969). With most noises, however, the hearing loss increases Iinearly with the average noise level which becomes deleterious at about $80 \mathrm{~dB}$ sound pressure level (Ward, 1963; Ward, et al., 1958). For example, the proportionate changes on the hearing threshold produced by $100 \mathrm{~dB}$ to $110 \mathrm{~dB}$ noises will be about the same as those produced by $110 \mathrm{~dB}$ to $120 \mathrm{~dB}$. 
Duration

Another important consideration in the damage potential of a given noise stimulus is the total duration of exposure. The lowering of hearing threshold is nearly linear as a function of the logarithm of time (Ward, 1963; Ward, et al., 1958). For example, if a given noise were capable of producing a $5 \mathrm{~dB}$ threshold shift in 10 minutes, it would take 100 minutes to produce a $10 \mathrm{~dB}$ threshold shift. This duration parameter becomes a major determinant of permanent hearing damage associated with high intensity noises over a period of years.

\section{Type of Noise}

Noise may be classified as either continuous or intermittent, regardless of its longitudinal duration. When the exposure to noise is intermittent or varies in sound pressure level. with time, the action of the middle ear muscles becomes an important consideration. The short rest periods afforded these muscles between bursts of noise is enough, at least, to partially restore their contractile strength. When the exposure is to low frequency noise, below $2 \mathrm{k} \mathrm{Hz}$, the protective action of these middle ear muscles can account for as much as $70 \%$ reduction in the amount of hearing loss (Ward, 1962b). These muscles, however, have no effect at higher frequency noises, near $4 \mathrm{k} \mathrm{Hz}$. For most intermittent noises, within a large range 
of exposure burst times, the hearing loss at $4 \mathrm{k} \mathrm{Hz}$ is proportional to the on-fraction (Ward, 1963; Ward, et al., 1958). For example, if during a specified period of time an intermittent noise has an intensity of $90 \mathrm{~dB}$ sound pressure level (SPL) $50 \%$ of the time and $110 \mathrm{~dB}$ SPL the rest of the time, it will produce a shift in hearing that is equal to that produced by a $100 \mathrm{~dB}$ noise acting continuously. Since a continuous noise level does not have the brief interruptions during which less deleterious levels are experienced, the exposure to a continuous noise level can be seen to pose a greater hazard to human hearing than exposure to an intermittent noise of the same duration and frequency spectra (Kryter, 1970).

CONSEQUENCES OF NOISE ON HEARING THRESHOLDS

Serial audiograms of persons exposed to intense levels of noise show a characteristic progression of hearing loss. Early losses first appear at the frequencies between $3 \mathrm{k}$ and $6 \mathrm{k} \mathrm{Hz}$. Usually, the first measurable frequency affected is $4 \mathrm{k} \mathrm{Hz}$ and then in time, the loss spreads in both directions until hearing for most of the audible frequencies $(20$ to $20,000 \mathrm{~Hz}$ ) is affected (Ward, 1963, 1965). The extent of the spread depends upon the amount of noise exposure sustained. Unfortunately, impaired hearing is not usually noticed until the losses in the speech 
frequencies 500, 1000 and $2000 \mathrm{~Hz}$ are $15 \mathrm{~dB}$ or more (Glorig, 1970). Substantial losses may occur at frequencies from 3000 to $6000 \mathrm{~Hz}$ without producing any subjective awareness of changes in hearing. The production of noiseinduced hearing loss is often a slow and progressive process, and years of exposure may elapse before any noticeable loss of hearing occurs (Glorig, 1970). There are many characteristics of the listener which are important when considering the production of noise-induced hearing loss. For example, it has not yet been established that age, sex and many aspects of general body condition do not play a role in individual susceptibility (Ward, 1963). The range of individual differences in the amount of loss produced by specific exposures to noise is quite large. For reasons not entirely known, individuals tend to vary with respect to their relative resistance to the effects of noise. These resistance or susceptibility characteristics and predictive tests which attempt to measure these characteristics have been the subject of much research. Ward, et al.(1959), in discussing individual susceptibility to noise, claims that it would be naive to believe that a bimodal distribution exists between "tough" and "tender" ears. Most researchers are skeptical that a single universal susceptibility index will ever be found (Glorig, 1970; Kryter, 1970; Ward, 1963). 
TEMPORARY THRESHOLD SHIFT

Noise affects the ability of the ear to detect weak signals following noise exposure. When this phenomenon occurs on a temporary basis, the inability to detect weak auditory signals is termed temporary threshold shift (TTS) because the decrease in sensitivity eventually disappears (Glorig, 1970; Lipscomb, 1970; Ward, 1963). Auditory fatigue (TTS) is, therefore, a time-linked process which not only grows with duration of exposure but also disappears as a function of time since exposure (Ward, 1961).

Preliminary data indicate that there is a definite relationship between the amount of permanent threshold shift (PTS) present and the amount of temporary threshold shift (Glorig, 1970). As permanent loss associated with a given noise stimulus increases, the amount of temporary threshold shift correspondingly decreases. This relationship, according to Glorig, remains almost linear until the permanent loss becomes so great that the effects of TTS are minimized and no longer measurable.

In summary, Kryter (1970), states that many similarities exist between TTS and PTS. Within the limitation of exposures up to 8 hours per day and TTS and PTS up to approximately $40 \mathrm{~dB}$, the following rules seem reasonably well established: 
1. The greatest amount of shift from a given noise band occurs within one octave above the frequency of the noise band for both TTS and PTS.

2. The frequency regions most susceptible to TTS are likewise most susceptible to PTS.

3. The locus of TTS and PTS appears to be in the hair cells and their supporting cells in the sense organ of hearing.

4. TTS from a given source does not increase as the exposure time is increased from 8 to 48 hours; however, the time required for recovery from these longer exposures is often several days in quiet.

5. It is highly probable that the pattern of TTS shown by a given ear to a given noise will develop a similar PTS with long-term continued exposure to the same noise. The sensitivity in a person, however, to develop a TTS from one frequency band of noise does not mean he will be equally sensitive to a different frequency band of noise.

6. The recovery in time following exposure from TTS occurs at one-half the rate of its growth in time during exposure.

An unfortunate trend seems to be emerging in our modern-day living. Now that considerable effort is being extended to bring the working environment under 
control with respect to industrial noise exposure, the oto-hazardous characteristics of our recreational and environmental noises are becoming increasingly apparent. A worker whose occupational noise exposure index is marginally acceptable according to present federal guidelines (U. S. Department of Labor, 1971) may still suffer ear damage from partaking in noisy non-occupational activities. It is quite possible that one's occupational noise exposure is insufficient to cause permanent ear damage. It is possible also that the same person's non-occupational activities alone are not oto-hazardous. But, if the two types of exposure are combined regularly into the same 24 hour period, the cumulative effect of noise exposure may be sufficient to result in damage to the hearing mechanism.

CONSEQUENCES OF NOISE ON MOTORCYCLE RIDERS

Motorcycles presently are enjoying a tremendous amount of popularity throughout the nation. This is evidenced by the rapid increase in motorcycle registrations in the last ten years. In Oregon alone, registrations have increased from 8,624 in 1960 to 58,671 in 1970 (Oregon Motorcycle Manual, 1971-72). Motorcycle enthusiasm is not without problems. Nationally, the death rate in motorcycle accidents in 1968 was four times as high as 
for motor vehicle accidents in general (Oregon Motorcycle Manual, 1971-72). Of less significance is the possible, insidious damage to the hearing mechanism of the motorcyclist due to the high levels of noise that most motorcycles are capable of producing.

Abbott (1972) reports that motorcycle noise ranges all the way from 30 to $140 \mathrm{~dB}$ or more and that cycle megaphones or expansion chamber type exhaust systems will produce noise levels at the operator's ear of at least $110 \mathrm{~dB}$. Certainly no one questions the potential of a motorcycle to produce noise levels which exceed the annoyance threshholds of even the most tolerant ears.

While the annoyance aspects of motorcycle noise are perhaps a more general and widely recognized social problem, the concern of the present research is with the more specific problem of possible damage to the hearing mechanism of the motorcyclist.

To date, there has been no research dealing specifically with the oto-hazardous potential of motorcycle noise as predicted by TTS. Researchers, however, have begun to alert the public to the deleterious efforts of various other environmental and recreational noises. Rock and roll music (Rintelmann, 1970), small private aircraft (Cohen, et al., 1970), lawn mowers (Shearer and Stevens, 1968), snowmobiles (Bess and Poynor, 1972), fire- 
crackers, sporting firearms and even various toy guns (Cohen, et al., 1970) all have been reported to produce sound pressure levels which are potentially hazardous to the hearing mechanism. The lack of any supportive research dealing with TTS among motorcyclists, and the fact that many drivers report a "ringing" tinnitus and temporary loss of hearing after rides of even short duration have prompted the present research.

Present Oregon law requires that motorcyclists wear "approved" helmets while cycling (Oregon Motorcycle Manual, 1971-72). Since all the motorcyclists screened for this study were of the opinion that their helmets created more noise than they attenuated at speeds above $35 \mathrm{mph}$, it seemed apparent that the wearing of a helmet while cycling constitutes a variable which could be significant in the production of TTS. The helmet can be thought of as a sort of resonating chamber for the driver's head. While most helmets are lined, they are lined with materials which are selected for their ability to withstand impact and absorb shock, not for their noise attenuation characteristics. Abbott (1972) reports that the newer "space" helmets, which are highly recommended for crash protection, actually act like a funnel and collect noise due to the fact that they do not seal around the ears. The wind noise generated by the helmet is an aerodynamic noise as opposed to 
an edge tone or a noise generated by the shedding of vortices. Apps. (1957), in discussing the different types of wind noise, states that aerodynamic noises are generated in the boundry layer as air flows over a surface. According to Apps, this noise has a random-type spectrum with frequency components throughout the audible range and into the ultrasonic range. While it's possible that some types of helmets may be capable of generating an edge tone, the particular helmet used in this study was described by the subjects as generating a "rushing" or random-spectrum type noise.

It would seem that since motorcycles are driven at moderate to high speeds, some consideration should be given to the friction noises (wind noise) generated by the air foil on the operators helmet: Motorcycle operators have noted that the force of the wind at high speeds actually elevates the helmet on the wearer's head, creating an additional potential for frictional noise exposure. It seems possible that at higher speeds, this wind noise factor might constitute a more deleterious hearing hazard than the overall vehicular noise level.

\section{PURPOSE}

The purpose of the present investigation will be to determine if there is a temporary threshold shift in the hear- 
ing of motorcycle riders wearing protective helmets. Consideration will be given to the possible effects on hearing from friction noises generated by the air foil on the rider's helmet.

It is the hypothesis of the present study that wind noise constitutes a significant, contributing factor toward the production of temporary threshold shift among a select sample of helmeted motorcycle riders. 
CHAPTER III

\section{METHOD}

\section{SUBJECTS}

The criteria for selecting subjects for this study required that they be old enough to legally own and operate a motorcycle and their pure-tone air-conducted thresholds were at least 0 dB American National Standards Institute (ANSI) as reported by Ventry, et al. (1971) or better at the frequencies $3 \mathrm{k}, 4 \mathrm{k}$ and $6 \mathrm{k} \mathrm{Hz}$. A 0 dB ANSI threshold criteria was used because of the 20 minute exposure limitation imposed by the equipment used in this study. It was felt that subjects with poorer threshold's might not experience any TTS from such a short exposure. The subjects used in this study were selected after threshold tests of more than 30 male motorcycle owners, between the ages of 18 and 30 years, failed to provide a single subject who could meet the $0 \mathrm{~dB}$ criteria. Five female subjects, none of whom operated a motorcycle, ultimately were selected. These subjects ranged in age from 18 to 27 years with a median age of 24. Ward (1959) maintains that with normal-hearing college students, men and women show equal amounts of TTS when exposed to the same noise. 
EQUIPMENT

Pure-tone air-conduction thresholds were obtained with a portable audiometer (Maico Model MA-16) with TDH-39 earphones mounted in MX 4I/AR cushions. This system was checked for calibration immediately before and after each testing session using Bruel and Kjaer instrumentation. Calibration was checked utilizing the American National Standards Institute's (ANSI) data as reported by Ventry, et al., (1971). The audiometer was powered by a portable power unit which consisted of an industrial rated Delco 12 volt cell battery and a Terado Model 50-167 power inverter. The voltage output of this portable power unit was monitored during all tests with a recently calibrated Simpson Model 260 volt-ohm-meter.

All sound level readings were taken with a Bruel and Kjaer sound level. Ineter (Model 2303 SLM and 1613 Octave Filter) using the $A$ weighting scale commensurate with the recognized procedures for measuring the damage potential of enviromental noises.

All pure-tone, air-conduction tests were administered in a portable, sound proof environment which met or exceeded the minimum ANSI standards in the octave bands for puremtone testing (Ventry, et al., 1971).

A Honda model 350 motorcycle was selected for use in this study because of its popularity and size. This 
two cylinder, medium-sized, stock production model motorcycle was equipped with a pair of standard mufflers.

The helmets used in this study were all Bell "500"'s selected for each subject on the basis of their subjective report that it "fit" them and that it would be comfortable to wear for the duration of the test exposures. Each helmet was marked and the subject wore the same helmet for all exposure conditions.

\section{PROCEDURE}

The procedure involved the exposure of 5 helmeted subjects to three separate aspects of noise associated with the operation of a motorcycle. First, each subject was exposed to 20 minutes of motorcycle noise in absence of measurable wind noise. This was accomplished by mounting the motorcycle on a Cycl-Dyn Dynamometer, a device which can simulate actual driving conditions, in terms of mechanical performance, as determined by brake horsepower and rpm. In other words, the dynamometer was adjusted so that it produced the same mechanical demands upon the stationary motorcycle as traveling down the highway at 60 miles per hour. That is, engine load, drivetrain noise and vibrations appeared commensurate to paved road conditions. Subjects were seated in the saddle with their hands on handle bars and instructed to assume a pos- 
ture consistent with actually operating the motorcycle. A sound pressure level reading taken at the operator's ear while the motorcycle was running on the dynamometer was found to be 92-94 dBA. Figure 1 shows an octave band analysis of the motorcycle noise as measured at the operator's ear.

In Condition II, each subject was exposed to $20 \mathrm{~min}-$ utes of $60 \mathrm{mph}$ wind noise. This was done by allowing the subject to stand in a Volkswagen equipped with a sun roof after the vehicle achieved a speed of $60 \mathrm{mph}$. A position was maintained which allowed each subject's head to be the maximum distance from any possible engine noise. The subject's head was approximately two feet above the top of the vehicle. This position served to minimize the possibility that the air foil from the top of the car might create air turbulances which would contaminate the frictional wind noises generated by the subject's helmet. Chen (1972) stated that, under the conditions of this study, the relative increase in wind velocity at the subject's head, due to the air foil of the Volkswagen, would be limited to approximately $1.6 \mathrm{mph}$ maximum. Consequently, the influence of additional wind stream generated by the vehicle, if such were operative at the ear of the subject, would be minimal.

Several sound pressure level readings, taken at the 


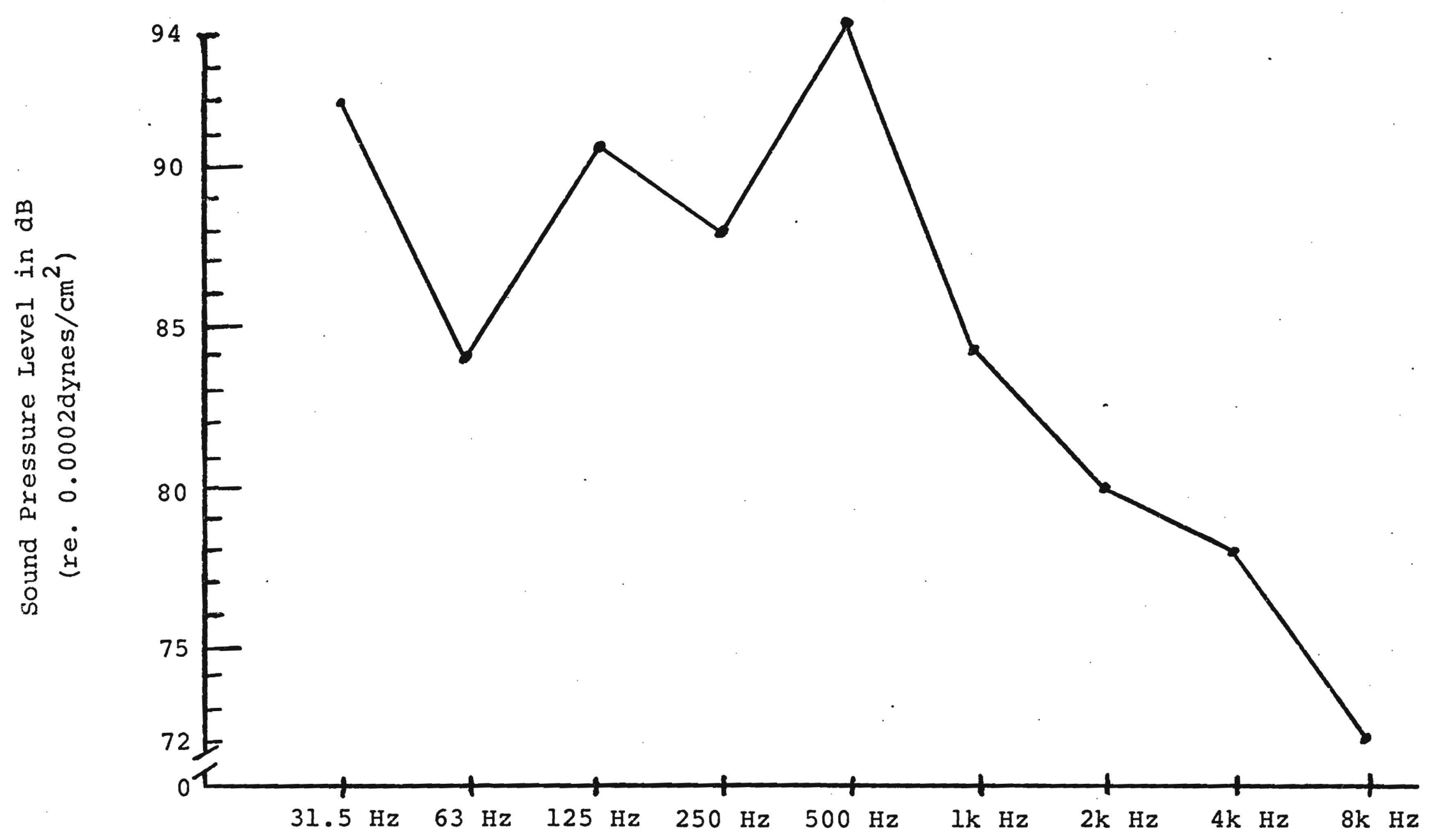

Figure 1. Octave band analysis of the motorcycle only noise (Condition I) as measured at the operator's ear.

เ 
subject's head with the engine operating in an rpm range necessary to maintain a $60 \mathrm{mph}$ speed, but with the vehicle stationary, were all found to be less than $70 \mathrm{dBA}$.

In Condition III, each helmeted subject was exposed to a 20 minute ride, while occupying the operator's saddle. The motorcycle operator was seated behind the subject during the noise exposure ride. The motorcycle assumed a speed of $60 \mathrm{mph}$ within 10 seconds and maintained this speed for the 20 minute duration. The highway site selected for this aspect of the study was a level stretch of class A paved road. All data involving wind noise was obtained on a day when the ambient wind velocity was less than $10 \mathrm{mph}$ as measured by Taylor "Windscope" anemometer.

A minimum of 72 hours elapsed between each exposure condition. During this period, all subjects were asked to avoid unusually loud or noisy environments.

All subjects were tested by pure-tone audiometry prior to each noise exposure condition and within 2 minutes after exposure using the modified Hughson-Westlake technique as described by Carhart and Jerger (1959). The test frequencies consisted of $3 \mathrm{k}, 4 \mathrm{k}$ and $6 \mathrm{k} \mathrm{Hz}$. The order of frequencies tested, as well as right and left ears, was varied randomly in an effort to avoid any possible ordering effect. Because TTS tends to decay as a direct function of the time interim between cessation of noise stimulus and 
onset of audiometric testing, the use of a relatively brief exposure period $(20 \mathrm{~min}$.$) necessitated that only$ data from the first ear tested be considered in the analysis. The duration of the audiometric test, therefore, could be limited to approximately one minute. 
CHAPTER IV

RESULTS

PRESENTATION OF RESULTS

The results of this study clearly support the hypothesis that wind noise was a significant factor in the production of TTS in this selected sample of helmeted motorcycle riders. The data (Table I) show that the least amount of TTS occurred with Condition I, the motorcycle only exposure. In Condition I, all subjects experiencing TTS had their greatest shift at only one of the test frequencies. In the other two conditions, Condition II (wind noise) and Condition III (motorcycle ride), some of the subjects experienced their maximum shift at two of the test frequencies. The greatest amount of TTS for all subjects occurred with the motorcycle ride (Condition III). Figure 2 shows a comparison of the mean threshold shifts at each frequency for the three different noise exposure conditions. Mean threshold shifts for the 5 subjects exposed to the combined effects of motorcycle and wind noise (Condition III) were $9 \mathrm{~dB}$ at $3 \mathrm{k}, 11 \mathrm{~dB}$ at $4 \mathrm{k}$ and $9 \mathrm{~dB}$ at $6 \mathrm{k} \mathrm{Hz}$. The wind noise exposure (Condition II) produced only slightly less TTS than the motorcycle ride. The motorcycle only exposure (Condition I), however, produced very little TTS. 


\section{TABLE I}

SUMMARY OF TEMPORARY THRESHOID SHIFT AFTER

A 20 MINUTE EXPOSURE TO THREE

DIFFERENT NOISE CONDITIONS

Amount of TTS at test frequency

Subject
(motorcycle
only)
1
2
3
4
5

$3 \mathrm{k} \mathrm{Hz}$

5

0

0

0

5

(wind noise only)

1

2

3

4

5

- (motorcycle ride)

1

2

3

4

5
5

10

10

10

10
1

5 .

10
$4 \mathrm{k} \mathrm{Hz}$

$6 \mathrm{k} \mathrm{Hz}$

5

0

0

5

0

0

0

5

0

0

10
10

10

5

10

15
10

10

15

5

5

10

5

15

20

10

10

5

10

15

10

5

5

10 


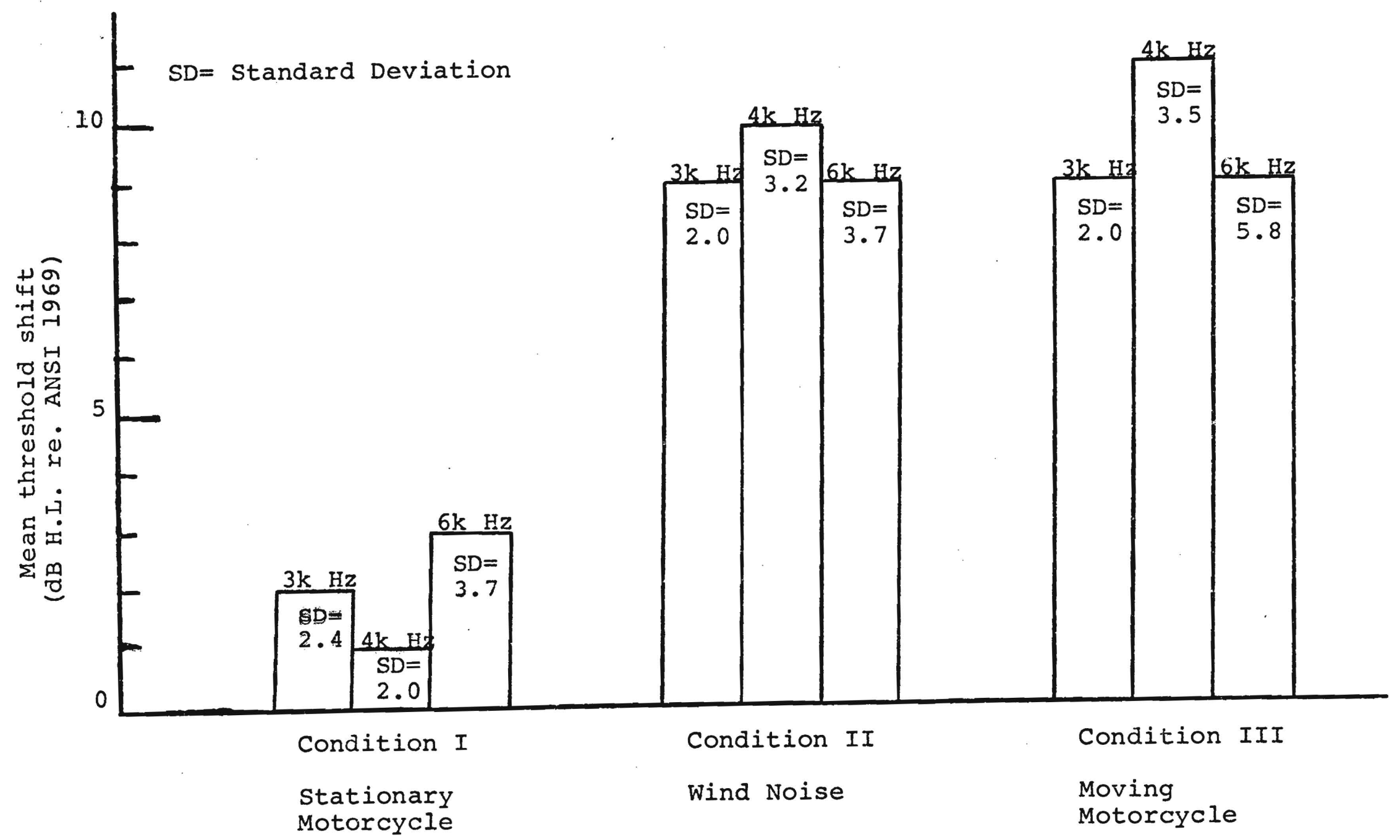

Figure 2. Comparison of mean threshold shifts at each frequency for the three different exposure conditions. 
The significance of the differences between the mean scores of the three conditions was examined statistically by means of the t-test (Thompson, 1965). These results revealed significant differences beyond the .05 level of confidence in mean TTS between Condition I (motorcycle only) and Condition II (wind only). The observed differences were significant at all test frequencies (see Table II). The mean differences between Condition I (motorcycle only) and Condition III (motorcycle ride) also were significant at all frequencies tested. However, the differences between wind noise only (Condition II) and motorcycle ride noise (Condition III) were not significant. Both Condition II (wind noise only) and Condition III (motorcycle and wind noise combined) produced significantly more TTS than the stationary motorcycle (Condition I) Table II.

Mean threshold shifts as a function of frequency were greatest at $4 \mathrm{k} \mathrm{Hz}$ for both moving cycle and wind conditions (see Figure 2). It is doubtful, however, whether the differences in average amount of TTS across subjects between $3 \mathrm{k}, 4 \mathrm{k}$ and $6 \mathrm{k} \mathrm{Hz}$ were significant for these two conditions, since the mean differences between any two of these test frequencies were no greater than 2 dB (Figure 2). The standard deviations at $4 \mathrm{k} \mathrm{Hz}$ were quite similar, 3.5 for motorcycle moving and 3.2 for the wind only condition. Similarly, the standard deviations at $3 \mathrm{k} \mathrm{Hz}$ were identical 


\section{TABLE II}

MEAN TTS AND STANDARD DEVIATIONS ASSOCIATED WITH THE THREE TREATMENT CONDITIONS ARE EXPRESSED. THIS TABLE REPORTS T SCORES COMPARING THE MEAN DIFFERENCES OF THE VARIOUS CONDITIONS.

Test Frequency

$3 \mathrm{k} \mathrm{Hz}$ $4 \mathrm{k} \mathrm{Hz}$ $6 \mathrm{k} \mathrm{Hz}$

\begin{tabular}{|c|c|c|c|c|c|c|c|}
\hline Condition & & mean & $S D$ & mean & SD & mean & SD \\
\hline $\begin{array}{c}\text { Condition } \\
\text { Condition } \\
t \text { score }\end{array}$ & $\begin{array}{l}\text { I } \\
\text { II }\end{array}$ & $\begin{array}{l}2 \\
9 \\
3.5 *\end{array}$ & $\begin{array}{l}2.4 \\
2.0\end{array}$ & $\begin{array}{l}1 \\
10 \\
3.67 \text { * }\end{array}$ & $\begin{array}{l}2.0 \\
3.2\end{array}$ & $\begin{array}{l}3 \\
9 \\
3.21 *\end{array}$ & $\begin{array}{l}3.7 \\
3.7\end{array}$ \\
\hline $\begin{array}{c}\text { Condition } \\
\text { Condition } \\
t \text { score }\end{array}$ & $\begin{array}{l}\text { I } \\
\text { III }\end{array}$ & $\begin{array}{l}2 \\
9 \\
3.5 *\end{array}$ & $\begin{array}{l}2.4 \\
2.0\end{array}$ & $\begin{array}{l}1 \\
11 \\
3.65 \text { * }\end{array}$ & $\begin{array}{l}2.0 \\
3.5\end{array}$ & $\begin{array}{l}3 \\
9 \\
2.45 * *\end{array}$ & $\begin{array}{l}3.7 \\
5.8\end{array}$ \\
\hline $\begin{array}{c}\text { Condition } \\
\text { Condition } \\
t \text { score }\end{array}$ & $\begin{array}{l}\text { II } \\
\text { III }\end{array}$ & $\begin{array}{l}9 \\
9 \\
0 * * *\end{array}$ & $\begin{array}{l}2.0 \\
2.0\end{array}$ & $\begin{array}{l}10 \\
11 \\
1 * * *\end{array}$ & $\begin{array}{l}3.2 \\
3.5\end{array}$ & $\begin{array}{l}9 \\
9 \\
0 * * *\end{array}$ & $\begin{array}{l}3.7 \\
5.8\end{array}$ \\
\hline
\end{tabular}

* significant at 0.025

** significant at 0.05

*** no significant difference 
for the two conditions, (S.D.=2). At $6 \mathrm{k} \mathrm{Hz}$, however, standard deviations of 5.8 (motorcycle moving) and 3.7 (wind noise only) indicated a greater variability of individual susceptability between the two conditions than at any other frequency. The pronounced influence of temporary threshold shift at this frequency on subject 2 following exposure to wind and motor noise (Condition III) would appear to account for this greater variance (see Figure 3). This subject obtained the greatest shift, $20 \mathrm{~dB}$, at $6 \mathrm{k} \mathrm{Hz}$ for this condition than for any other condition or test frequency among all five subjects. The most vulnerable test frequency for this subject was $6 \mathrm{k} \mathrm{Hz}$ following all three conditions (see Figure 3 ).

All subjects experienced threshold shifts at all test frequencies after exposure to the wind only (Condition II) and moving cycle (Condition III). Following exposure to the stationary cycle (Condition I), one subject (S-4) did not reveal a threshold shift at any test frequency. Data from other subjects revealed shifts at one or more frequencies; for example, S-1, S-2 and $\mathrm{S}-3$ experienced higher thresholds at one frequency only, while s-5 revealed a shift at two test frequencies (see Figure 3 ).

\section{DISCUSSION OF RESULTS}

The results of this study clearly indicate that, 

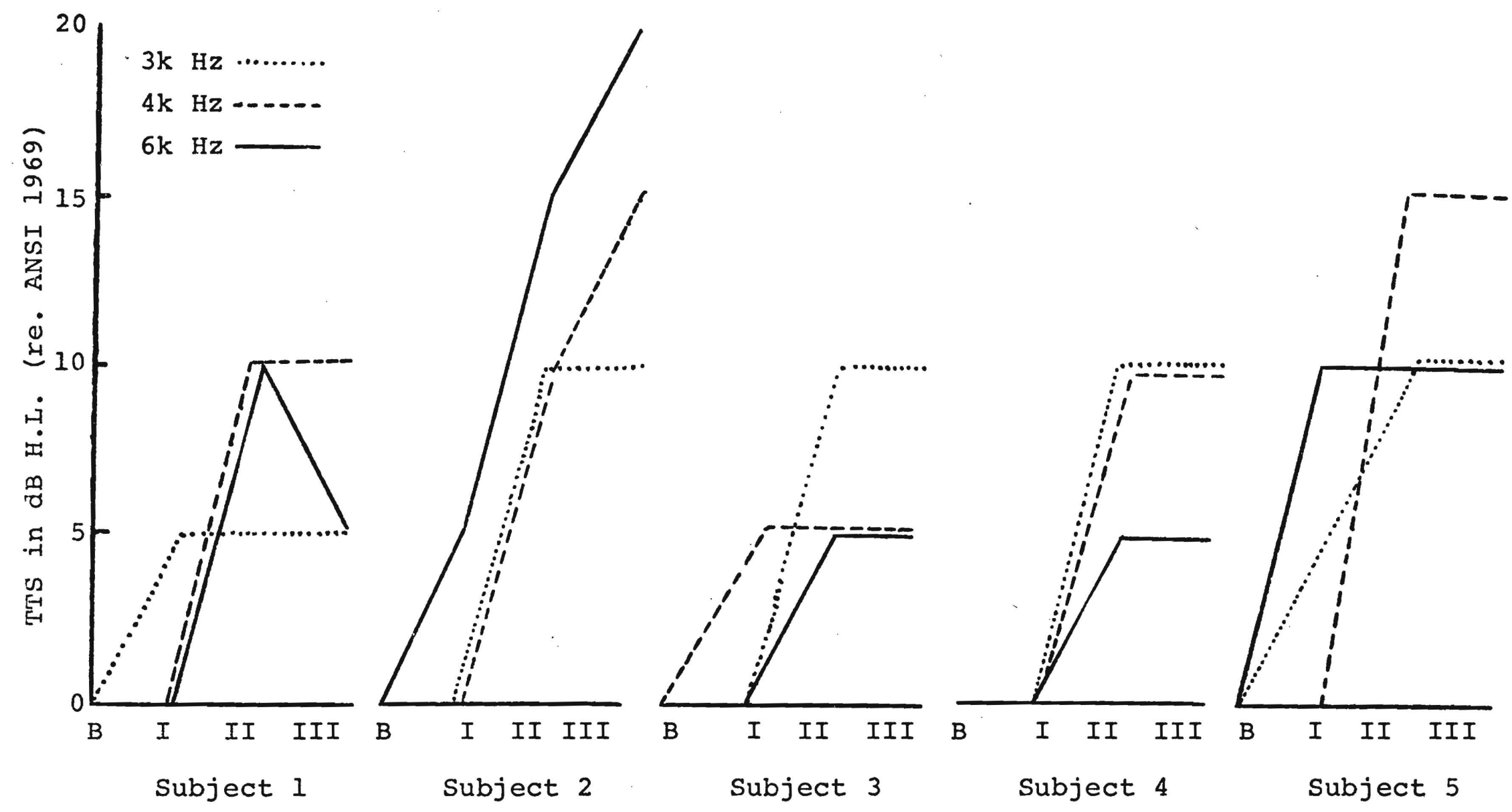

Figure 3. Individual threshold shifts at $3 \mathrm{k}, 4 \mathrm{k}$ and $6 \mathrm{k} \mathrm{Hz}$ associated with three noise conditions (I, motorcycle only; II, wind noise only; III, motorcycle and wind noise combined) following baseline (B) audiometric testing. 
within the limitations of the sample size, there was a significant difference between the amount of TTS produced by the motorcycle only (Condition I) and the amount of TTS produced by both the wind noise (Condition II) and the motorcycle ride (Condition III). There was very little difference, however, in the amount of TTS produced by the wind noise (Condition II) and the moving cycle (Condition III). All t-tests, comparing the mean threshold shifts at the three test frequencies, indicated that there were no significant differences. The slight difference observed between wind noise exposure data and that of the motorcycle ride noise might be attributable to the vibration factor present on the motorcycle. Wheeler (1950) demonstrated that noise and vibrations in combination will produce greater TTS than noise alone. Others, Broadbent (1957, 1958), Peterson and Gross (1963) have reported on the deleterious effects of noise-related vibrations.

One of the most significant variables in this study was the helmet. The Bell "500" helmet was selected because of its popularity among motorcycle enthusiasts. The helmet variable in a subsequent replication of this study could vary the findings in either direction depending upon brand and "fit." Obviously, in order to provide effective noise attenuation, a helmet will have to seal tightly against the head around the perimeter of the helmet. Because of the 
variation in size, head and face shape among individuals, this would almost certainly require that each helmet be individually custom-molded to fit. Even if we assume that someone could afford to have such a helmet made, it is extremely unlikely that anyone could stand the discomfort of such a tight fitting device enclosing that much of his head, i.e., the heat, pressure and perspiration would probably be unbearable even for short periods of time.

The noise exposure periods were limited to $20 \mathrm{~min}-$ utes due to limitations imposed by operating a motorcycle on a dynamometer. An air cooled motorcycle engine relies upon large volumes of fairly high velocity air to keep the engine within safe operating temperature. Twenty minutes of standing still, without forced air cooling, operating under a $60 \mathrm{mph}$ load, is pushing the safe heat range to the maximum limit. Research should be directed toward investigating wind noise over longer durations.

In the initial selection of subjects, threshold tests of 30 motorcycle operators failed to produce a single subject whose hearing threshold met the criteria for this study. It seems, therefore, that motorcycle operation must be considered along with 40 million industrial workers, as a hazardous occupation.

In the present study, a portable manual audiometer was used in order to facilitate the limitations imposed by 
the portable power supply. The minimum hearing level on this audiometer was $0 \mathrm{~dB}$. It is quite possible that some of the subjects actually had better than $0 \mathrm{~dB}$ thresholds. A further limitation was the fact that this audiometer's hearing level dial was graduated in $5 \mathrm{~dB}$ increments. These limitations suggest that with a more sensitive testing instrument, the TTS could have been greater than that which was actually measured by the equipment used in this study. The present study reveals a need for further research employing a larger sample, longer noise exposures and more sophisticated instrumentation. Such investigations should be directed toward a definitive analysis of the variables associated with wind exposure. For example, a wind tunnel would eliminate the need for a motorized vehicle for gathering wind noise data. It also might allow for greater generalizations to other wind-related operations such as sailboating, riding in cars with the windows down or in convertibles.

Future investigations on helmets might serve to modify such variables as size, design, fit, and the amount and type of materials used in the helmet lining. The size of the motorcycle and the speed at which it travels no doubt have a bearing on the potential danger to the operator's hearing. More research might predict maximum size or types of motorcycles or at least safe 
operating speeds if oto-hazardous levels of noise can be avoided while riding a motorcycle. 
CHAPTER V

CONCLUSIONS AND IMPLICATIONS

\section{SUMMARY}

The present study investigated the significance of wind noise as a contributing factor toward the production of TTS among a select sample of motorcycle riders.

Five normal-hearing, helmeted, female subjects were administered pure-tone air-conduction hearing tests immediately before and within 2 minutes after exposure to three noise related aspects of motorcycle riding. The amount of hearing loss present at $3 \mathrm{k}, 4 \mathrm{k}$ and $6 \mathrm{k} \mathrm{Hz}$ after each 20 minute exposure condition was recorded as the TTS for that subject. The three conditions consisted of motorcycle noise only, wind noise only, and motorcycle and wind noise combined.

The results of the investigation revealed that wind noise was indeed a significant factor $(p>.05)$ toward the production of TTS among motorcycle riders.

\section{CONCLUSIONS}

On the basis of the data collected in the investigation, the following conclusions seem warranted:

1. Wind noise is the single most significant factor in the hearing losses sustained by helmeted motorcycle 
riders at $60 \mathrm{mph}$.

2. Wind and engine noise, associated with motorcycle operation, are of sufficient intensity to produce a temporary loss of hearing.

3. Permanent loss of hearing can undoubtedly be produced by riding a motorcycle over an extended period of time.

\section{IMPLICATIONS FOR FURTHER RESEARCH}

The present study has opened many possibilities for further investigations.

1: It would be of interest to investigate the effects of different types of helmets.

2. Would a judiciously selected helmet-size minimize the effects of wind noise?

3. Would the same thesis hold true with a larger sample and increased exposure?

4. What would a comparison of helmeted versus nonhelmeted subjects reveal? More specifically, which air foil noise would provide the most TTS, the air foil of the helmet or the air foil without a helmet?

5. What effect would a larger or smaller motorcycle have upon the results?

6. What effect would varying speeds have upon the TTS provided by the wind only condition and the motorcycle 
and wind noise combination?

7. What effect does wind noise, associated with other operations, such as sailboating, cars with windows down or convertibles have on the hearing mechanism?

8. There is a real need for more sophisticated equipment, e.g., a wind tunnel without the adjunct of employing a motorized vehicle (Volkswagen). The possible additive effect of a less than $70 \mathrm{dBA}$ noise then could be removed from the wind only condition. 


\section{BIBLIOGRAPHY}

Abbott, A., "Hearing Conservation." Cycle World, 11:84-6, February, 1972 .

Apps. D. C., "Automobile Noise". In: Handbook of Noise Control, edited by Harris, C.M. New York: McGrawHill, 1957.

Bess, F. H., and Poynor, R. E., "Snowmobile Engine Noise." Arch. Otolaryng. 95:164-8, February, 1972.

Broadbent, D. E., "Effects of Noise on Behavior." In: Handbook of Noise Control, edited by Harris, C. M. New York: McGraw-Hill, 1957.

Broadbent, D. E., Perception and Communication. London: Pergamon Press, 1958.

Carhart, R., and Jerger, J. F., "Preferred Method For Clinical Determination of Pure-Tone Threshold." JSHD, 24:330-45, November, 1959.

Chen, P. I., Personal Interview, Portland State University, Portland, Oregon, July, 1972.

Glorig, A., "Hearing Conservation in Industry." Maico Audiological Library Series, 2:4-16, Reports 2 , 3 and $4,1970$.

Kryter, K. D., The Effects of Noise on Man. New York: Academic, 1970 .

Lipscomb, D. M., "Important Considerations In The Use of Hearing Conservation Guidelines." Maico Audiological Library Series, 8:1-10, Reports 1 and 2, 1970.

Oregon, Department of Transportation, Motor Vehicles Division. Oregon Motorcycle Manual, 1971-72, 20 pp.

Peterson, P. G., and Gross, E. E., Handbook of Noise Measurement. West Concord: General Radio Corporation, 1963.

Rintelmann, W. F., "A Review of Research Concerning Rock and Roll Music and Noise-Induced Hearing Loss." Maico Audiological Library Series, 8:24-7, Report 7, 1970. 
Shearer, W. M., and Stevens, G. H., "Acoustic Threshold

Shift From Power Lawn Mower Noise." Sound Vibration,

2:19, October, 1968 .

Thompson, Richard F., Statistical Methods Useful in Medicine. Portland, Oregon: Department of Public Health and Preventative Medicine 1965.

U. S. Department of Labor, Safety Standards, Washington, D. C.: U. S. Government Printing Office, 20: 7-11, May-June, 1971.

Ventry, I. M., Chaiklin, J. V., and Dixon, R. F., Hearing Measurement. New York: Appleton-Century-Crofts, 1971.

Ward, W. D., "Auditory Fatigue and Masking." In: Modern Developments in Audiology, edited by Jerger, J. F. New York: Academíc, 1963.

34. "Damage Risk Criteria For Line Spectra." JASA, 34: 1610-19, October, 1.962a. , "Effects of Noise on Hearing." In: Noise As A Public Health Hazard, ASHA Report No. 4, pp. 40-8, 1969 .

, "Noninteraction of Temporary Threshold Shifts." JASA, 33 : 1512-3, November, 1961.

, "Studies On The Aural Reflex II. Reduction Of Temporary Threshold Shift From Intermittent Noise By Reflex Activity; Implications For Damage-Risk Criteria." JASA, 34:234-41, February, 1962b.

"Temporary Threshold Shifts Following Monaural And Binaural Exposure." JASA, 38:121-5, July, 1965.

Ward, W. D., Glorig, A., and Skalar, D. L., "Dependence of Temporary Threshold Shift at $4 \mathrm{kc}$ on Intensity And Time." JASA, 30:944-54, October, 1958.

Ward, W. D., Glorig, A., and Skalar, D. L., "Temporary Threshold Shift From Octave Band Noise: Applications To Damage-Risk Criteria." JASA, 31:522-8, April, 1959.

Ward, W. D., Glorig, A., and Selters, W., "Temporary Threshold Shift In A Changing Noise Level." JASA, 32:235-7, February, 1960 . 


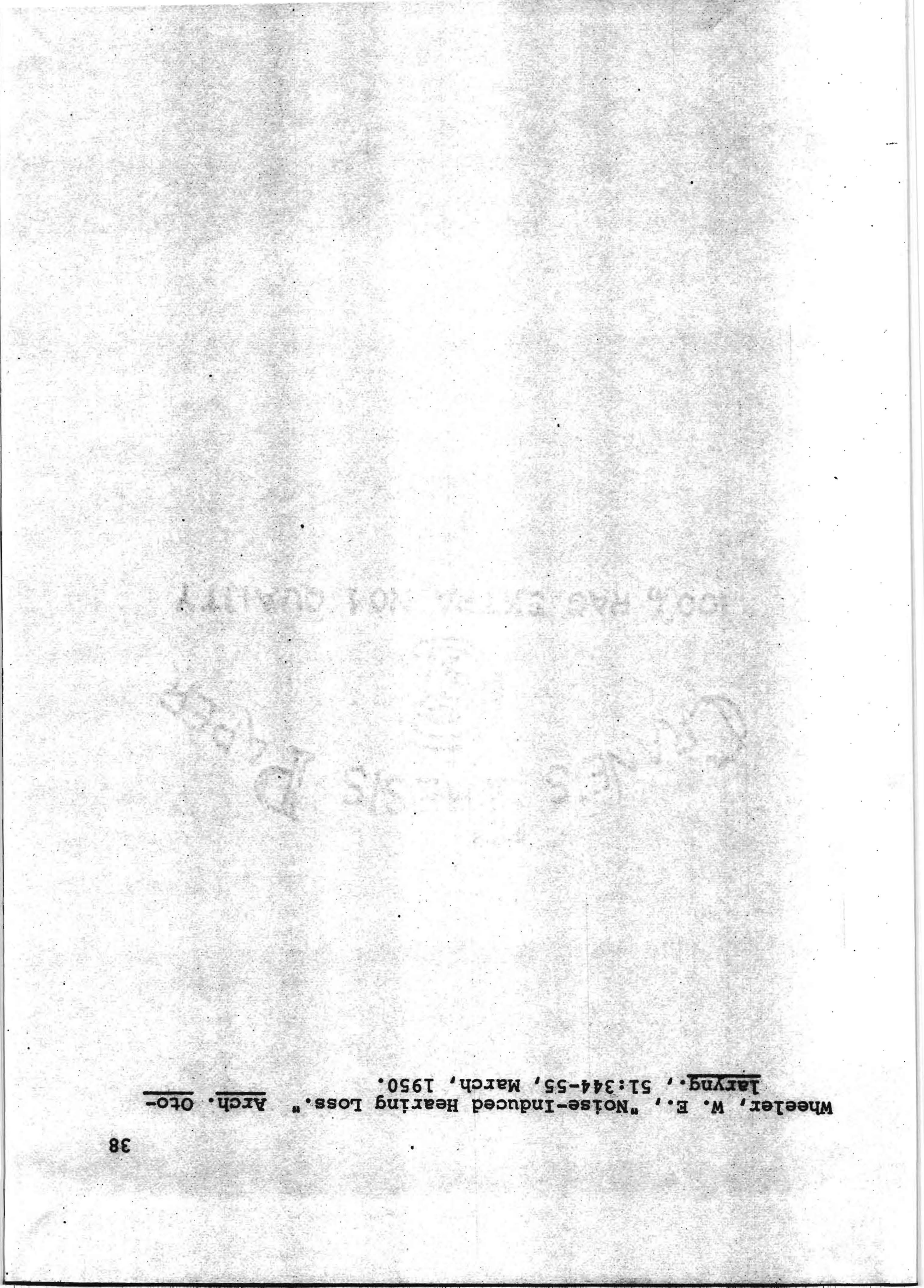

